\title{
Healthcare student-patient relationship and the quality of the clinical learning environment - a cross-sectional study
}

\author{
Arja Suikkala ${ }^{1,2^{*}} \mathbb{D}$, Leena Timonen ${ }^{3}$, Helena Leino-Kilpi ${ }^{2,4} \mathbb{D}$, Jouko Katajisto ${ }^{5}$ (D) and Camilla Strandell-Laine ${ }^{6}$ (D)
}

\begin{abstract}
Background: Relationships with patients are seen as the core component of establishing the quality of patientcentred care and promoting patients' autonomy and relevant use of services. A clinical learning environment that emphasizes relationship-based healthcare is essential for encouraging future healthcare professionals to work in partnership with patients. There is also broad agreement that the insight of patients should be used actively in healthcare students' clinical learning. The aim of this study was to describe healthcare students' perceptions of their relationship with patients and the quality of the clinical learning environment and to identify factors associated with both of these.

Methods: A cross-sectional survey using an electronic questionnaire was applied to collect data from 1644 Finnish healthcare students, mostly nursing students, between January 2018 and May 2018. The data were analysed statistically using descriptive statistics, Spearman's correlation coefficients, and multifactor analysis of variance.

Results: Students perceived the level of the student-patient relationship and the role of the teacher as good while pedagogical atmosphere, premises of care, premises of learning, and supervisory relationship were perceived to be at very good level. The correlations between the student-patient relationship and all clinical learning environment dimensions were perceived as moderate. Furthermore, a number of student-related factors associated with the student-patient relationship and the quality of the clinical learning environment were detected.

Conclusions: In this study, the rarely explored perspective of the student-patient relationship within the context of the clinical learning environment was included. The student-patient relationship and the quality of the clinical learning environment were perceived as good by the students, with a number of determining factors affecting these perceptions. Giving the student-patient relationship a role in clinical education may be conducive to students' learning with the patient in focus, and may thus promote the competence needed in the rapidly evolving healthcare environment and the changing scope of clinical practice.
\end{abstract}

Keywords: Clinical learning environment, Cross-sectional study, Healthcare students, Student-patient relations, Supervision, Teacher

\footnotetext{
* Correspondence: arja.suikkala@diak.fi

${ }^{1}$ Diaconia University of Applied Sciences, Kyläsaarenkuja 2, Fl- 00580 Helsinki,

Finland

${ }^{2}$ Department of Nursing Science, University of Turku, Turku, Finland

Full list of author information is available at the end of the article
}

(c) The Author(s). 2021 Open Access This article is licensed under a Creative Commons Attribution 4.0 International License, which permits use, sharing, adaptation, distribution and reproduction in any medium or format, as long as you give appropriate credit to the original author(s) and the source, provide a link to the Creative Commons licence, and indicate if changes were made. The images or other third party material in this article are included in the article's Creative Commons licence, unless indicated otherwise in a credit line to the material. If material is not included in the article's Creative Commons licence and your intended use is not permitted by statutory regulation or exceeds the permitted use, you will need to obtain permission directly from the copyright holder. To view a copy of this licence, visit http://creativecommons.org/licenses/by/4.0/ The Creative Commons Public Domain Dedication waiver (http://creativecommons.org/publicdomain/zero/1.0/) applies to the data made available in this article, unless otherwise stated in a credit line to the data. 


\section{Background}

Health professional education aims to produce sufficient, adequately distributed and qualified health professionals responsive to the health needs of populations. At the same time, the global shortage and maldistribution of healthcare professionals is prompting both educational institutions and healthcare organisations to create enabling environments for caring and learning in order to enhance the motivation, attraction and retention of a well-trained future healthcare workforce that is able to adapt to the diverse and changing needs and expectations of individual patients [1-3].

The healthcare student-patient relationship constitutes the core of competence-based health care education [4, 5]. The idea of learning with rather than about patients is emerging and spreading, calling for patients to adopt more active roles and bring their expertise and voice into healthcare education. Focusing learning on the student-patient relationship offers patients a variety of opportunities for educational and evaluation-related roles that can enrich students' clinical learning and evaluation and thus promote students to provide holistic comprehensive care. Thus, all patients with experience and capacity can participate in learning relationships with students and thereby improve the overall quality of the education. However, within the context of studentpatient relationships it is paramount to ensure patient safety and patients' informed consent of whether or not to participate in students' learning and assessment $[5,6]$.

In the literature, different student-patient relationships have been described where patients' level of participation has ranged from a passive role in the learning activities initiated by supervisors to more active and collaborate roles facilitating students' learning [6-8]. Facilitative student-patient relationships engage students and patients in mutually beneficial dialogue and shared learning that benefits both. This means that the students listen and respond to the patients' concerns and wishes. Through knowing the patients personally students encourage and act as advocates for the patients. The patients, in turn, have expertise of their own situation and participate in the learning relationship with the students by expressing opinions and providing the students with information and advice on matters related to their experienced state of health and care. By providing valuable feedback on students' performance from the patient's point of view patients have an opportunity to bolster students' confidence and competency development $[8,9]$.

Patient relationships are determined by the clinical learning environment (CLE) in terms of the type, quality and amount of communication, attitudes and behaviours displayed by students, patients, supervisors, and the interprofessional team in the practicum placement. Students succeed in creating positive encounters with patients, and a good atmosphere, with a supervisor in a supportive role, thus promotes patients' active role in contributing to student learning [6, 7]. The student supervision is provided by clinical staff supervisors who balance between the safe care of patients and the learning of a student or group of students assigned to a personal supervisor or supervisors who vary according to shift or place of work [10-14]. As the clinical environment can be stressful for students as a result of both new relationships and a new environment, feeling welcomed and accepted as an equal member in interprofessional teamwork is of great importance $[12,15,16]$.

Individualised supportive supervision and continuous feedback based on students' learning needs, goals, stage of learning and the contribution of a teacher often hired by educational institutions have been found to be crucial for positive learning experiences [10, 17, 18]. Although teachers' pedagogical role in the integration of theory and practice and their support and guidance for students' professional development have been well acknowledged, their actual presence in the clinical placements has been gradually replaced by increasing use of information and communication technology for remote student-teacher interaction $[19,20]$.

Meaningful patient relationships with positive CLE experiences can determine students' achievement of learning outcomes, self-confidence, and even their intention to remain in the healthcare profession $[8,21]$. Students who are actively involved in establishing positive interpersonal relationships and adopt responsibility for their own learning facilitated by an individual relationship with a supervisor and a teacher, are often more satisfied with the CLE than students who are given more of an observational role [12, 13, 15, 21, 22]. Furthermore, longer practicum periods and the time spent on direct patient contacts are seen as crucial for providing positive learning experiences that foster students' professional confidence and competence in planning, delivering and evaluating care in partnership with patients [13, 23, 24].

Increasingly, there are educational initiatives where patients are involved in the clinical training of healthcare professionals to inspire the supervision of students, with the patient in focus. Nevertheless, there is scarcity of research on the student-patient relationship in the context of CLE [6, 13, 25].

The aim of this study was to describe healthcare students' perceptions of their relationship with patients and the quality of CLE and to identify factors associated with both of these.

The following research questions were addressed:

1. What are healthcare students' perceptions of the student-patient relationship? 
2. What are healthcare students' perceptions of the quality of the CLE?

3. What is the association between the patient relationship and the quality of the CLE?

4. What factors are associated with the studentpatient relationship and the quality of the CLE?

\section{Methods}

\section{Design, sample and data collection}

This study used cross-sectional survey data collected from healthcare students between 1st January and 31st May 2018 in one university hospital district. The university hospital district was made up of five hospital areas and 23 hospitals representing the largest hospital district in Finland. The data collected using an electronic questionnaire by the hospital district was part of the quality assessment and development of clinical learning environments and supervision. All healthcare students who participated in a clinical placement in the Spring 2018 semester were asked to complete the questionnaire during the last week of their clinical practicum. Instructions for answering the survey were given by the students' supervisors.

The data consisted of a total of 1664 responses from healthcare students who volunteered to answer the questionnaire. The data represented $33.0 \%$ of all healthcare students $(N=5042)$ in the university hospital district who were practising in clinical placements in the study year 2018. The students, most of whom were studying towards registered nurse qualification, were completing a university of applied sciences degree programme defined in the Bologna Declaration and in the EU directives [26-28]. A minority of the students were studying in a social and healthcare degree programme provided by vocational institutions [29-31]. In most cases, the students had reserved the clinical placements, which had been confirmed by their teachers as appropriate for the students' stage of training. The students were thus completing their clinical practicum in a variety of specialty fields.

\section{Instrument}

The data were collected using the Student Feedback Questionnaire. The Student Feedback Questionnaire was developed for the purposes of national benchmarking in Finland [32] to collect benchmark data of the studentpatient relationship, the quality of the CLE, and information about students' background (13 items).

The Student-Patient Relationship (SPR) Scale included 13 items measuring a facilitative student-patient relationship and thus offering a more comprehensive understanding of the CLE where the patients are in focus. The items were based on a literature review [9], interview study [8] as well as testing with both nursing students and patients [33-35].

For the Student Feedback Questionnaire, the CLE was measured by using the CLES+T Scale that had been modified suitable for healthcare students together with the developer of the CLES+T Scale. For that purpose, two items of the original CLES+T Scale describing the ward manager as a team member and the ward as a good learning environment were deleted. In contrast, three items describing well-organised basic familiarization, use of patient cases in the student supervisory process and supervisor's supervision skills that support learning were added [36]. In this study, The CLES+T Scale included the following dimensions: pedagogical atmosphere (7 items), premises of care (4 items), premises of learning (7 items), supervisory relationship (8 items), and role of the teacher (9 items) [32, 37, 38]. The original CLES+T Scale has been used in several different languages, cultures and contexts mostly for nursing students [11, 18, 22, 24, 39, 40], but more recently, for other health professional students as well [36, 41-43].

In both scales, an 11-point Likert scale $(0=$ strongly disagree, $10=$ strongly agree) was used. In the interpretation of descriptive statistics, the mean values were divided into four equal parts in order to describe the level of students' perceptions: very weak (0-2.0), weak (2.1-4.0), satisfactory (4.1-6.0), good (6.1-8.0), and very good (to be pursued 8.1-10).

\section{Data analysis}

The data were analysed using SPSS 22.0 (SPSS Inc., Chicago, USA) software and described by using frequencies, percentages, means and standard deviations (SD). Dependencies between the student-patient relationship (SPR Scale) and CLE (CLES + T Scale) were examined with Spearman's rho correlation coefficient. This was the first study examining the student-patient relationship and the quality of the CLE in the same study. Therefore, multifactor analysis of variance was used to find a more comprehensive understanding of the background factors associated with the studentpatient relationship (SPR Scale) and the quality of CLE in terms of all five dimensions of the CLES + T Scale.

\section{Ethical considerations}

The study followed the principles of research ethics [44, 45] and the General Data Protection Regulation [46] (Regulation EU 2016/679). Research permission was obtained from the university hospital district according to the organization's ethical committee policies. The informed consent page of the questionnaire contained the legally required data protection information to allow students to make an informed decision of whether to participate in the survey or not. By answering the 
questionnaire and pressing the submit button, students gave informed consent for the use of their answers for both benchmarking and research purposes. Students completed the electronic questionnaire completely anonymously via a secure connection. The data were processed as confidential and the privacy of the participants was protected.

\section{Results}

\section{Student characteristics}

Of the 1644 students, most were at least 25 years old, studying in a degree programme leading to registered nurse qualification, and in their second and third year of studies. The students were mostly undertaking a clinical placement of four to more than 6 weeks. In most cases, the students had a mid-term feedback session. Most of the students achieved their clinical learning goals and received supervision that supported their professional development at least fairly well. However, only about two thirds perceived that their theoretical studies supported learning in clinical practice very well or fairly well. A detailed description of the students' characteristics is presented in Table 1.

\section{Students' perceptions of the student-patient relationship}

The student-patient relationship was perceived as good. In more detailed examination, the mean scores over 8.1 were at very good level in six out of 13 items. Patients instructed students in care activities was the only item that was perceived to be at satisfactory level.

The internal consistency of the SPR Scale was evaluated calculating Cronbach's coefficient alpha, which indicated acceptable reliability (Table 2 ).

\section{Students' perceptions of the quality of the CLE}

In general, students were very satisfied with the quality of the CLE (Table 3). They perceived the pedagogical atmosphere, premises of care, premises of learning, and supervisory relationship as very good and the role of the teacher as good. The supervisory relationship was rated the highest. The five highest rated items were those in Supervisory relationship describing mutual respect and approval in the supervisory relationship (mean 9.2, SD 1.6), supervisors' positive attitude towards supervision (mean 9.2, SD 1.6), students' individual supervision (mean 9.2, SD 1.6) and mutual interaction in the supervisory relationship (mean 9.1, SD 1.7), and in premises of learning describing the use of patient cases in the supervisory process (mean 9.1, SD 1.6).

The role of the nurse teacher received the lowest ratings (Table 3). At item level, the five lowest rated items out of nine were those describing teacher's ability to integrate theoretical knowledge into practice of patient care (mean 7.3, SD 2.5), teacher and clinical team working in supporting student learning (mean 7.0, SD 3.0 ), teacher helping the student to reduce the theorypractice gap (mean 6.8, SD 2.7), teacher's expertise to the clinical team (mean 5.3, SD 3.2), and teacher as a member of the clinical team (mean 5.1, SD 3.2). Furthermore, the internal consistency of the CLES + T Scale indicated acceptable reliability (Table 3 ).

\section{The association between the student-patient relationship} and the quality of the CLE

A statistically significant positive correlation was found between the student-patient relationship and the quality of the CLE. Spearman's $r$-values ranged from 0.32 to $0.35(p<.0001)$ indicating moderate positive linear correlation $(r=0.3-0.5)$ between the student-patient relationship and all five dimensions of CLES $+\mathrm{T}$ Scale (Table 4).

\section{Factors associated with the student-patient relationship and the quality of the CLE}

The student-patient-relationship was perceived as significantly better among nursing, public health nursing, midwifery, paramedic nursing, practical nurse, physiotherapist, and occupational therapeutics students and those with more than 6 weeks' clinical practicum compared to biomedical laboratory scientist students and students with 4-5 weeks' clinical placement ( $p$-values ranged from .05 to $<.0001)$. Students who had a midterm feedback session $(p=.004)$ gave significantly higher scores on the student-patient relationship compared to those without this session. Students who achieved their learning goals during the placement very well perceived the student-patient relationship as significantly better compared to those who achieved their learning goals fairly well or moderately ( $p$-values ranged from .006 to < .0001). Students perceived the student-patient relationship as significantly better if the theoretical studies supported their clinical learning very well or fairly well compared to students who reported moderate or quite poor support ( $p$-values ranged from .025 to .008); the same was true for students with supervision supporting professional development very well compared to students with supervision supporting professional development quite poorly ( $p$-values ranged from .037 to .008). (Table 5).

Several statistically significant factors associated with the quality of CLE were found (Table 5). As for degree programmes, occupational therapy students perceived the premises of care as significantly better than biomedical laboratory scientist students $(p=.045)$. Pedagogical atmosphere and premises of learning were perceived as significantly better among students with a clinical practicum of 3 weeks or less than those with 4-5 weeks ( $p$ values ranged from .027 to .017). Students with a named 
Table 1 Characteristics of the healthcare students ( $n=1656-1664)$

\begin{tabular}{ll} 
Socio-demographic and background factors related & \multicolumn{2}{c}{ Students } \\
to the clinical practicum & $n$
\end{tabular}

Age in years

$<20$

$20-24$

$25-29$

$\geq 30$

Previous professional qualifications ${ }^{a}$

Yes

No

Current phase of studies

First year

Second year

Third year

Fourth year

Degree programme

Registered nurse

Registered nurse, public health nurse

Registered nurse, midwife

Radiographer

Registered nurse, paramedics

Biomedical laboratory scientist

Practical nurse for social and healthcare ${ }^{b}$

Physiotherapist

Occupational therapist

Something else (e.g. audiometrist, podiatrist, dental hygienist)

Duration of clinical practicum

$\leq 3$ weeks or less

4-5 weeks

$\geq 6$ weeks

Occurrence of supervision

A named personal supervisor and a working relationship

A named personal supervisor, but not a working

relationship

The supervisor changed during the placement

No named supervisor at all

Supervisor varied according to shift or place of work

A group supervisor rather than an individual supervisor

Discussion about learning goals with a named supervisor ${ }^{a}$

$$
\text { Yes }
$$

No

Having a mid-term feedback session ${ }^{\text {a }}$

Yes

No

124975.1

$147 \quad 8.8$

$\begin{array}{ll}13 & 0.8\end{array}$

$\begin{array}{ll}28 & 1.7\end{array}$

$178 \quad 10.7$

$\begin{array}{ll}49 & 2.9\end{array}$

159296.1

$64 \quad 3.9$
Table 1 Characteristics of the healthcare students $(n=1656-1664)$ (Continued)

\begin{tabular}{|c|c|c|}
\hline \multirow{2}{*}{$\begin{array}{l}\text { Socio-demographic and background factors related } \\
\text { to the clinical practicum }\end{array}$} & \multicolumn{2}{|c|}{ Students } \\
\hline & $\mathrm{n}$ & $\%$ \\
\hline \multicolumn{3}{|l|}{ Having a mid-term feedback session ${ }^{a}$} \\
\hline Together with supervisor and nurse teacher & 585 & 44.8 \\
\hline With supervisor & 673 & 51.6 \\
\hline With healthcare educator & 47 & 3.6 \\
\hline \multicolumn{3}{|l|}{ Achievement of clinical learning goals } \\
\hline Very well & 998 & 60.0 \\
\hline Fairly well & 602 & 36.2 \\
\hline Moderately & 57 & 3.4 \\
\hline Quite poorly & 6 & 0.4 \\
\hline Very poorly & 1 & 0.1 \\
\hline \multicolumn{3}{|l|}{ Supervision supported professional development ${ }^{\mathrm{a}}$} \\
\hline Very well & 1131 & 68.1 \\
\hline Fairly well & 429 & 25.8 \\
\hline Moderately & 89 & 5.4 \\
\hline Quite poorly & 11 & 0.7 \\
\hline Very poorly & 1 & 0.1 \\
\hline \multicolumn{3}{|l|}{ Summative evaluation session at the end of the placement ${ }^{a}$} \\
\hline Yes & 1574 & 94.7 \\
\hline No & 88 & 5.3 \\
\hline \multicolumn{3}{|l|}{ Summative evaluation session at the end of the placement ${ }^{a}$} \\
\hline Together with supervisor and nurse teacher & 673 & 42.9 \\
\hline With supervisor & 868 & 55.3 \\
\hline With the nurse teacher & 28 & 1.8 \\
\hline \multicolumn{3}{|l|}{ Theoretical studies supported learning in clinical practice ${ }^{a}$} \\
\hline Very well & 316 & 19.0 \\
\hline Fairly well & 732 & 44.0 \\
\hline Moderately & 487 & 29.3 \\
\hline Quite poorly & 19 & 7.2 \\
\hline No theoretical studies before the placement & 9 & 0.5 \\
\hline
\end{tabular}

Recommendation of the clinical practicum placement to peer students ${ }^{a}$

\begin{tabular}{lll} 
Very positively & 1204 & 72.4 \\
Positively & 278 & 16.7 \\
Probably yes & 138 & 8.3 \\
Probably no & 35 & 2.1 \\
No in any case & 7 & 0.4 \\
\hline Missing data & & \\
bocational training and qualifications for social and healthcare takes about 3 \\
years to complete and does not fall within the EU directives
\end{tabular}

personal supervisor and a well-working supervision relationship regarded the pedagogical atmosphere, premises of care, premises of learning and supervisory relationship as significantly better than those with a named supervisor and poorly-working relationship ( $p$-values ranged from .012 to $<.0001)$. They also gave significantly higher 
Table 2 Students' perceptions of student-patient relationship $(n=1664)$

\begin{tabular}{|c|c|c|c|}
\hline Brief description of item content of SPR Scale & Number of items & Cronbach's a & $\begin{array}{l}\text { Students }(n=1664) \\
\text { Mean }^{\mathrm{a}}(\mathrm{Sd})\end{array}$ \\
\hline Facilitative student-patient relationship & 13 & .90 & $7.9(1.6)$ \\
\hline Mutual understanding in students' and patients' best interest. & & & $9.1(1.5)$ \\
\hline Student listened to patients' concerns. & & & $8.7(2.0)$ \\
\hline Student encouraged patients. & & & $8.7(1.9)$ \\
\hline Student discussed confidential matters with patients. & & & $8.5(2.1)$ \\
\hline Student talked with patients about their emotions. & & & $8.4(2.1)$ \\
\hline Student's actions were guided by patients' wishes. & & & $8.2(2.2)$ \\
\hline Student knew patients as individuals. & & & $8.0(2.5)$ \\
\hline Patients as experts of their own situation. & & & $8.0(2.2)$ \\
\hline Patients presented views about care. & & & $8.0(2.3)$ \\
\hline Patients provided valuable information about illness. & & & $7.8(2.5)$ \\
\hline Student acted as patient advocate. & & & $7.7(3.0)$ \\
\hline Patients gave feedback on student actions. & & & $6.5(2.9)$ \\
\hline Patients instructed students in care activities. & & & $4.4(3.2)$ \\
\hline
\end{tabular}

${ }^{\mathrm{a}}$ Very weak $=0-2.0$, Weak $=2.1-4.0$, Satisfactory $=4.1-6.0$, Good $=6.1-8.0$, Very good (to be pursued) $=8.1-10$

ratings on the premises of learning than those with a group supervisor rather than an individual supervisor, as well as on the supervisory relationship than those with no named supervisor or whose supervisors varied according to shift or place of work ( $p$-values ranged from .016 to .001) (Table 5).

Pedagogical atmosphere, premises of learning and supervisory relationship were perceived as significantly better among students who discussed their learning goals with a named supervisor compared to those who did not ( $p$-values ranged from .031 to <.0001). Students who had a 'half-way' feedback session and students who had a summative evaluation session with their supervisor and teacher at the end of the placement perceived the role of the teacher as significantly better compared to those with no half-way feedback session and those with summative evaluation only with their supervisor, respectively ( $p$-values $(p<.0001)$. Students who achieved their learning goals during the placement very well regarded the pedagogical atmosphere as significantly more positive than those who achieved their learning goals fairly well or moderately whereas the opposite was true for premises of care, premises of learning and supervisory relationship ( $p$-values ranged from .025 to < .0001). Students with supervision that supported their professional development very well regarded the pedagogical atmosphere, premises of care and supervisory relationship and the role of the teacher as significantly more positive than all the others ( $p$-values ranged from .001 to <.0001) (Table 5).

Students with theoretical studies that supported their learning during the clinical practicum very well perceived the premises of care as significantly better than those with theoretical studies supporting their learning moderately $(p<.0001)$. Furthermore, students with theoretical studies supporting their learning in clinical practice fairly well evaluated the pedagogical atmosphere, premises of care and premises of learning as significantly better than students with theoretical studies supporting their learning in clinical practice moderately ( $p$-values ranged from .030 to .003). Students with any theoretical studies supporting their learning in clinical practice

Table 3 Summary of students' perceptions of the quality of CLE $(n=1664)$

\begin{tabular}{llll}
\hline Dimensions of the quality of CLE & Number of items & Cronbach's a & $\begin{array}{l}\text { Students ( } \boldsymbol{n}=\mathbf{1 6 6 4 )} \\
\text { Mean }^{\mathbf{a}}(\mathbf{S d})\end{array}$ \\
\hline Pedagogical atmosphere & 7 & .88 & $8.5(1.5)$ \\
Premises of care & 4 & .81 & $8.5(1.4)$ \\
Premises of learning & 7 & .88 & $8.8(1.4)$ \\
Supervisory relationship & 8 & .97 & $9.0(1.6)$ \\
Role of the teacher & 9 & .93 & $6.9(2.4)$
\end{tabular}

${ }^{a}$ Very weak $=0-2.0$, Weak $=2.1-4.0$, Satisfactory $=4.1-6.0$, Good $=6.1-8.0$, Very good (to be pursued) $=8.1-10$ 
Table 4 Spearman's correlations between the student-patient relationship and the quality of the CLE $(n=1664)$

\begin{tabular}{lll}
\hline $\begin{array}{l}\text { Dimensions of the } \\
\text { quality of CLE }\end{array}$ & \multicolumn{2}{l}{ Student-patient relationship } \\
\cline { 2 - 3 } & $\boldsymbol{r}^{*}$ & $\boldsymbol{p}$-value \\
\hline Pedagogical atmosphere & .35 & $p<.0001$ \\
Premises of care & .34 & $p<.0001$ \\
Premises of learning & .33 & $p<.0001$ \\
Supervisory relationship & .33 & $p<.0001$ \\
Role of the teacher & .32 & $p<.0001$ \\
\hline
\end{tabular}

*The Spearman's correlation coefficient from .30 to .50 was interpreted as moderate positive correlation at the significance level of $p<.0001$

evaluated the role of the teacher as significantly better than those who had no theoretical studies before the placement $(p<.0001)$ (Table 5).

The more positively the students recommended their clinical placement unit to their peers, the better they perceived the pedagogical atmosphere, premises of care, premises of learning, and supervisory relationship ( $p$ values $<.0001)$. Those students who recommended the clinical placement unit very positively to their peers also perceived the role of the teacher as significantly better than those who did not recommend the unit at all $(p=$ .036) (Table 5).

\section{Discussion}

This study examined the student-patient relationship, the quality of the CLE and associated factors as perceived by healthcare students. A positive and supportive pedagogical atmosphere in terms of interaction, behaviour, attitudes and values on the part of supervisors, other staff, teachers and patients characterise the quality of CLE and thus determine students' learning experiences and clinical learning outcomes [11, 21, 24, 38]. In clinical education, emphasis on patient-centred care and enhancing patient autonomy and expertise in care are of great importance and thus shape the self-efficacy and competence of students in providing holistic healthcare $[2,47]$. Therefore, the perspective of the student-patient relationship offers a more complete understanding of the context of CLE [4-6].

In this study, the student-patient relationship was perceived as good among students. The quality of CLE was also moderately associated with students' perceptions of their relationships with patients, thus showing the student-patient relationship to be a core element of the CLE $[6,7,24]$. A sufficient and relevant theoretical basis of clinical practice, achievement of learning goals, and professional development supported by good quality supervision strengthen students' self-confidence, comfort level and their satisfaction with relationships with patients [11, 13] and the quality of the CLE [20]. Special attention needs to be paid to students who face challenges in meeting their intended learning goals during their placement due to issues such as insufficient theoretical knowledge base. Besides clinical training, the insight and expertise of patients should be used actively in healthcare students' theoretical studies in order to guarantee the best possible basis for patient-student interaction and patient-centred care in both single degree programmes and in interprofessional learning of healthcare students from more than one degree programme [11, 13].

Enabling and supporting the use of patients' expertise of experience in a more active manner, especially in providing an illustration of their illness and care, thus boosting students' understanding of what they have learned in theory, is of great importance [47]. By providing feedback on students' performance, patients have an important role in shaping the competence priorities for future health professionals [5, 6, 33]. Experiences of patient relationships can also enhance students' coping with the emotions and stress related to patient care while the role of supervisors and teachers is to help students deal with these emotions through debriefing [47, 48].

Longer practicum periods associated with better student-patient relationships allow better quality and more time being spent on direct patient contacts, and thus promote shared learning through dialogue between students and patients, benefiting both $[5,7,12,14]$. In contrast to earlier studies, the length of the clinical practicum does not necessarily guarantee the quality of the CLE $[18,24,40]$. Therefore, clinical practicums planned collaboratively by students, supervisors and teachers that give students independence, responsibility and support their level of competence enhance meaningful learning experiences with patients [11, 15, 22]. Moreover, studies with long-term follow-up of the impact on studentpatient relationships and the quality of CLEs are needed, especially in the clinical areas where patient-centred clinical education approach is used.

Overall, students' perceptions of the CLE in terms of pedagogical atmosphere, premises of care, premises of learning, and supervisory relationship indicated good quality. Furthermore, the quality of the CLE was linked to students' tendency to recommend their clinical practicum placement to peers [36] and may thus strengthen students' professionalism and likelihood to stay in the health workforce [40]. This study revealed the complexity and multidimensionality of the CLE with a number of crucial elements affecting students' perceptions of the quality of the CLE [49]. The results are in line with studies mostly conducted with nursing students $[11,17,24,40]$ but also among other healthcare students $[15,36]$. The supervision relationship has especially been shown to be a central factor that determines the CLE both in hospital, home-based or primary health care $[11,22,24,38,43,50]$ and nursing home contexts $[16,22]$. 
Table 5 Background factors related to the student-patient relationship and the quality CLE $(n=1664)$. Statistical procedure comprised multi-factor analysis of variance

\begin{tabular}{|c|c|c|}
\hline Background factors & Student-patient relationship and the quality CLE & $P$-value* \\
\hline \multirow[t]{2}{*}{ Degree programme } & Student-patient relationship & $<.0001$ \\
\hline & Premises of care & .023 \\
\hline \multirow[t]{3}{*}{ Duration of clinical placement } & Student-patient relationship & .030 \\
\hline & Pedagogical atmosphere & .022 \\
\hline & Premises of learning & .016 \\
\hline \multirow[t]{4}{*}{ Occurrence of supervision } & Pedagogical atmosphere & $<.0001$ \\
\hline & Premises of care & $<.0001$ \\
\hline & Premises of learning & $<.0001$ \\
\hline & Supervisory relationship & $<.0001$ \\
\hline \multirow[t]{3}{*}{ Discussion about learning goals with a named supervisor } & Pedagogical atmosphere & .031 \\
\hline & Premises of learning & $<.0001$ \\
\hline & Supervisory relationship & $<.0001$ \\
\hline \multirow[t]{2}{*}{ Having a mid-term feedback session } & Student-patient relationship & .004 \\
\hline & Role of the teacher & $<.0001$ \\
\hline \multirow[t]{5}{*}{ Achievement of clinical learning goals } & Student-patient relationship & $<.0001$ \\
\hline & Pedagogical atmosphere & $<.0001$ \\
\hline & Premises of care & $<.0001$ \\
\hline & Premises of learning & $<.0001$ \\
\hline & Supervisory relationship & $<.0001$ \\
\hline \multirow[t]{5}{*}{ Supervision supported professional development } & Student-patient relationship & .045 \\
\hline & Pedagogical atmosphere & $<.0001$ \\
\hline & Premises of care & $<.0001$ \\
\hline & Supervisory relationship & $<.0001$ \\
\hline & Role of the teacher & .001 \\
\hline Summative evaluation session at the end of the placement & Role of the teacher & $<.0001$ \\
\hline \multirow[t]{5}{*}{ Theoretical studies supported learning in clinical practice } & Student-patient relationship & $<.0001$ \\
\hline & Pedagogical atmosphere & .015 \\
\hline & Premises of care & $<.0001$ \\
\hline & Premises of learning & .005 \\
\hline & Role of the teacher & $<.0001$ \\
\hline \multirow[t]{5}{*}{ Recommendation of the clinical placement to peer students } & Pedagogical atmosphere & $<.0001$ \\
\hline & Premises of care & $<.0001$ \\
\hline & Premises of learning & $<.0001$ \\
\hline & Supervisory relationship & $<.0001$ \\
\hline & Role of the teacher & .020 \\
\hline
\end{tabular}

*The significance level for $p$-values was set at .05

The findings that the quality of CLE is affected by a named supervisor and the supervision proceeding as planned $[12,15,17,18,36,40]$ confirms students' preferences towards a personal supervisor. However, student-dedicated units with teamwork and collaboration between students under supervision, often from more than one professional discipline, combined with a patient-centred approach, have been shown to be a good alternative to individual supervision [7, 11, 12, 14]. Therefore, increasing patients' engagement in shaping future health professionals' competence to meet the health needs of patients also necessitates focusing learning on the student-patient relationships that are most desirable in interprofessional clinical learning environments with new coaching and supervising methods $[2,3,47]$. 
In line with other studies, the role of the teacher was perceived less positively than other dimensions of CLE $[24,36]$. This may be because during clinical placements, face-to-face contacts with teachers have increasingly been replaced by the use of various online collaboration methods $[20,40]$. Therefore, teachers are not necessarily regarded as members of the clinical care team, but regular contacts with them are considered important. Students need opportunities to reflect on their experiences with their supervisors and teachers, and they expect constructive feedback from both, not only at mid-term and final clinical evaluation, but also on an ongoing basis. Reflective discussions about individual learning goals and outcomes with the supervisor and teacher are essential for supporting students' professional development and determine their experienced quality of CLE $[15,17,36]$.

\section{Strengths and limitations}

This cross-sectional study represented Finnish healthcare students in a variety of different clinical practicum placements in one university hospital district where patients have been actively involved as experts of experience in the design, planning and delivery of health services, including clinical training of healthcare students. A large study dataset $(n=1644)$ increased the study's external validity; hence, the results may, with caution, be considered to be representative of the university hospital context in Finland. The questionnaire was not answered by all students having their clinical practicum. Thus, the students participating in the study might have caused a potential social-desirability bias, and the results might to some extent be specific to the sample.

Both scales were arranged on a 11-point Likert-scale so that the students could indicate their actual agreement scores. The scales included descriptive explanations of $0=$ strongly disagree $10=$ strongly agree, with labelled endpoints. The midpoint of the scale along with the endpoints would have decreased the number of nonresponses [51].

This study offers new insight into the healthcare student-patient relationship in the CLE context in the university hospital context. However, contextual differences in clinical practicum placements need to be considered. The university hospital district offers specialized medical care including outpatient clinics, inpatient wards and emergency units. Lack of unit-specific data regarding the students' clinical placements and the quality and time spent on direct care contacts with patients of different ages, health status and admission reasons can be regarded as a limitation of this study and needs to be the focus of future student-patient relationship research.

Even though the sub-sample of laboratory scientist students was very small, the questions concerning the student-patient relationship were found inappropriate for students working with no or scarce contact with patients. Therefore, it would be wise to extend the use of the SPR Scale only to those clinical placements that involve direct patient care contacts or client service practices.

\section{Conclusions}

Focusing on relationships with patients and the quality of CLE are crucially important for the professional development of healthcare students as they are expected to deliver high quality and patient-safe care after graduation. Therefore, the emphasis on student-patient relationships, as an untapped resource, deserves its full realisation in the CLE and the supervision of students, taking into account patients' consent and respecting their voluntary participation. Collaboration between educational institutions and healthcare organisations is needed in establishing a safe and supportive CLE with the aim of promoting patients' collaborative educational role and making it valued. Supervisors, for their part, need education and support on their role in the patientcentred approach in encouraging and supporting student learning, thus shifting the focus from themselves towards dialogue between students and patients.

\section{Abbreviations}

CLE: Clinical learning environment; SPR: Student-patient relationship; CLES+T: Clinical Learning Environment, Supervision and Nurse Teacher Scale

\section{Acknowledgements}

The authors thank all the healthcare students who volunteered to participate in this study. We would also like to thank the patients involved in the clinical training of the healthcare students taking part in this study. We would like to express our very great appreciation to Professor Riitta Meretoja for her valuable expertise during the planning and development of this study. The authors would also like to thank Anna Vuolteenaho for editing the English language.

\section{Authors' contributions}

A.S. was responsible for the conception and design of the study and interpretation of data. L.T. was responsible for clinical expertise, acquisition of data, and transmission of the data for analysis. H.L-K. has been involved in the development of Clinical Learning Environment Scale (CLES). J.K. had overall responsibility for the statistical analyses carried out and assisted with the interpretation of data. A.S. was responsible for drafting the manuscript and all authors (A.S., L.T., H.L-K., J.K., C.S-L.) revised it critically for important intellectual content. All authors read and approved the final manuscript. All those entitled to authorship are listed as authors.

\section{Funding}

No funding was obtained for this study.

\section{Availability of data and materials}

The data that support the findings of this study are available from the Helsinki and Uusimaa University Hospital District but restrictions apply to the availability of these data, which were used under license for the current study, and so are not publicly available. Data are however available from the authors upon reasonable request and with permission of the Helsinki and Uusimaa University Hospital District. 


\section{Declarations}

\section{Ethics approval and consent to participate}

The approval was obtained from the Helsinki and Uusimaa University Hospital (approval number $\$ 47 / 2018$ ). All methods were carried out in accordance with relevant guidelines and regulations. Informed consent was obtained from all participants, online, before completing the questionnaire.

\section{Consent for publication}

Not applicable.

\section{Competing interests}

The authors declare that they have no competing interests.

\section{Author details}

${ }^{1}$ Diaconia University of Applied Sciences, Kyläsaarenkuja 2, Fl- 00580 Helsinki, Finland. ${ }^{2}$ Department of Nursing Science, University of Turku, Turku, Finland. ${ }^{3}$ Helsinki University Hospital, Helsinki, Finland. ${ }^{4}$ Turku University Hospital, Turku, Finland. ${ }^{5}$ Department of Mathematics and Statistics, University of Turku, Turku, Finland. ${ }^{6}$ Novia University of Applied Sciences, Turku, Finland.

Received: 25 January 2021 Accepted: 14 April 2021

Published online: 22 April 2021

\section{References}

1. European Commission. Forces shaping and challenging the resilience of the health work force: European Commission; 2020. Available from: https:/ec. europa.eu/health/workforce/overview_en. Cited 2020 Oct 12

2. World Health Organization. Continuity and coordination of care: a practice brief to support implementation of the WHO Framework on integrated people-centred health services. Geneva: World Health Organization; 2018. Licence: CC BY-NC-SA 3.0 IGO. Available from: https://apps.who.int/iris/ha ndle/10665/274628. Cited 2020 Oct 14

3. World Health Organization. State of the world's nursing 2020: investing in education, jobs and leadership. Geneva: World Health Organization; 2020. Licence: CC BY-NC-SA 3.0 IGO. Available from: https://www.who.int/publica tions/i/item/9789240003279. Cited 2020 Oct 14

4. Fong S, Tan A, Czupryn J, Oswald A. Patient-centred education: how do learners' perceptions change as they experience clinical training? Adv Health Sci Educ Theory Pract. 2019;24(1):15-32. https://doi.org/10.1007/s104 59-018-9845-y.

5. Rowland P, Anderson M, Kumagai AK, McMillan S, Vija K, Sandhu VK, et al. Patient involvement in health professionals' education: a meta narrative review. Adv Health Sci Educ Theory Pract. 2018;24(3):595-617. https://doi. org/10.1007/s10459-018-9857-7.

6. Suikkala A, Koskinen S, Leino-Kilpi H. Patients' involvement in nursing students' clinical education: a scoping review. Int I Nurs Stud. 2018;84:4051. https://doi.org/10.1016/.jijnurstu.2018.04.010.

7. Bleakley A, Bligh J. Students learning from patients: let's get real in medical education. Adv Health Sci Educ Theory Pract. 2008;13(1):89-107. https://doi. org/10.1007/s10459-006-9028-0.

8. Suikkala A, Leino-Kilpi H. Nursing student-patient relationship: experiences of students and patients themselves. Nurse Educ Today. 2005;25(5):344-54. https://doi.org/10.1016/..nedt.2005.03.001.

9. Suikkala A, Leino-Kilpi H. Nursing student-patient relationship: a review of the literature from 1984 to 1998. J Adv Nurs. 2001;2001(33):42-50. https:// doi.org/10.1046/j.1365-2648.2001.01636.x.

10. Bergjan M, Hertel F. Evaluating students' perception of their clinical placements - testing the clinical learning environment and supervision and nurse teacher scale (CLES + T scale) in Germany. Nurse Educ Today. 2013; 33(11):1393-8. https://doi.org/10.1016/..nedt.2012.11.002.

11. Ekstedt $M$, Lindblad $M$, Löfmark $A$. Nursing students' perception of the clinical learning environment and supervision in relation to two different supervision models - a comparative cross-sectional study. BMC Nurs. 2019; 18(1):49. https://doi.org/10.1186/s12912-019-0375-6.

12. Forber J, DiGiacomo M, Carter B, Davidson P, Phillips J, Jackson D. In pursuit of an optimal model of undergraduate nurse clinical education: an integrative review. Nurse Educ Pract. 2016;21:83e92. https://doi.org/10.1016/ j.nepr.2016.09.007.
13. Gruppen L, Irby D, Durning S, Maggio L. Interventions designed to improve the learning environment in the health professions: a scoping review. MedEdPublish. 2018;7:73. https://doi.org/10.15694/mep.2018.0000211.1.

14. Jayasekara R, Smith C, Hall C, Rankin E, Smith M, Visvanathan V, et al. The effectiveness of clinical education models for undergraduate nursing programs: a systematic review. Nurse Educ Pract. 2018;29:116-26. https:// doi.org/10.1016/j.nepr.2017.12.006.

15. Salminen H, Öhman E, Stenfors-Hayes T. Medical students' feedback regarding their clinical learning environment in primary healthcare: a qualitative study. BMC Med Educ. 2016;16(1):313. https://doi.org/10.1186/s12 909-016-0837-4.

16. Skaalvik MW, Normann HK, Henriksen N. Clinical learning environment and supervision: experiences of Norwegian nursing students - a questionnaire survey. J Clin Nurs. 2011;20(15-16):2294-304. https://doi.org/10.1111/j.1365-2 702.2011.03727.x.

17. Papastavrou E, Dimitriadou M, Tsangari H, Andreou C. Nursing students' satisfaction of the clinical learning environment: a research study. BMC Nurs. 2016;15(1):44. https://doi.org/10.1186/s12912-016-0164-4.

18. Saukkoriipi $M$, Tuomikoski A-M, Sivonen $P$, Kärsämänoja $T$, Laitinen $A$, Tähtinen T, et al. Clustering clinical learning environment and mentoring perceptions of nursing and midwifery students: a cross-sectional study. J Adv Nurs. 2020;76:2336-47. https://doi.org/10.1111/jan.14452.

19. Saarikoski M, Kaila P, Lambrinou E, Cañaveras RMP, Tichelaar E, Tomietto M, et al. Students' experiences of cooperation with nurse teacher during their clinical placements: an empirical study in a Western European context. Nurse Educ Pract. 2013;13(2):78-82. https://doi.org/10.1016/j.nepr.2012.07.013.

20. Strandell-Laine C. Nursing student-nurse teacher cooperation using mobile technology during the clinical practicum. Annales Universitatis Turkuensis D1412. Turku: University of Turku, Faculty of Medicine, Nursing Science; 2019. http://urn.fi/URN:ISBN:978-951-29-7549-5

21. Flott $E A$, Linden $L$. The clinical learning environment in nursing education: a concept analysis. J Adv Nurs. 2016;72(3):501-13. https://doi.org/10.1111/ja n.12861.

22. Bisholt B, Ohlsson U, Engström AK, Johansson AS, Gustafsson M. Nursing students' assessment of the learning environment in different clinical settings. Nurse Educ Pract. 2014;14(3):304-10. https://doi.org/10.1016/j. nepr.2013.11.005.

23. Suikkala A. Nursing student-patient relationship and associated factors. Annales Universitatis Turkuensis D 788. Turku: University of Turku, Faculty of Medicine, Nursing Science; 2007. http://urn.fi/URN:ISBN:978-951-29-3463-8

24. Warne T, Johansson U, Papastavrou E, Tichelaar E, Tomietto M, den Bossche $\mathrm{KV}$, et al. An exploration of the clinical learning experience of nursing students in nine European countries. Nurse Educ Today. 2010;30(8):809-15. https://doi.org/10.1016/j.nedt.2010.03.003.

25. Ford K, Courtney-Pratt H, Marlow A, Cooper J, Williams D, Mason R. Quality clinical placements: the perspectives of undergraduate nursing students and their supervising nurses. Nurse Educ Today. 2016;37:97-102. https://doi. org/10.1016/j.nedt.2015.11.013.

26. European Ministers of Education. The Bologna process: setting up the European higher education area: European Ministers of Education; 1999. Available from: http://www.ehea.info/Upload/document/ministerial_declara tions/1999_Bologna_Declaration_English_553028.pdf. Cited 2020 Jun 25

27. Directive 2005/36/EC of the European parliament and of the council of 7 September 2005 on the recognition of professional qualifications. European Commission; 2005. Available from: http://eur-lex.europa.eu/legal-content/ EN/TXT/PDF/?Uri=CELEX:32005L0036\&rid=1. Cited 2019 Sep 14.

28. Directive 2013/55/EC of 20 November 2013 on the recognition of professional qualifications. Amendment to directive 2005/36/EC of the European Parliament and of the Council. European Commission; 2005. Available from: http://eur-lex.europa.eu/legal-content/EN/TXT/PDF/?uri= CELEX:32013L0055\&rid=1. Cited 2019 Sep 14.

29. Jørgensen $\mathrm{CH}$, Olsen OJ, Persson Thunqvist D, editors. Vocational education in the Nordic countries: learning from diversity, vol. 2: Routledge Research in International and Comparative Education: Routledge; 2018. https://doi. org/10.1080/13636820.2019.1617463.

30. Ministry of Education and Culture. Finnish Education System. Ministry of Education and Culture, 2020, 2017. Available from: https://minedu.i//en/ education-system. Cited 2020 Nov 2.

31. Vocational Education and Training Act 531/2017. Finnish Ministry of Justice. Available from: https://www.finlex.fi/fi/laki/alkup/2017/20170531 (In Finnish). [cited 2020 Nov 2] 
32. Meretoja R, Tarr T, Strandell-Laine C. The CLES scale as a national quality tool for clinical learning and teaching. In: Saarikoski M, Strandell-Laine C, editors. The CLES-scale: an evaluation tool for healthcare education. Cham: Springer; 2018. p. 47-53. https://doi.org/10.1007/978-3-319-63649-8_5.

33. Suikkala A, Koskinen S, Katajisto J, Leino-Kilpi H. Congruence between nursing students' and patients' views of student-patient relationships. Adv Health Sci Educ Theory Pract. 2020;10(1):79-115. https://doi.org/10.1007/s1 0459-020-09972-z

34. Suikkala A, Leino-Kilpi H, Katajisto J. Factors related to the nursing studentpatient relationship: the student's perspective. Nurse Educ Today. 2008a; 28(5):539-49. https://doi.org/10.1016/j.nedt.2007.09.004.

35. Suikkala A, Leino-Kilpi H, Katajisto J. Nursing student-patient relationships: a descriptive study of students' and patients' views. Int J Nurs Educ Scholarsh. 2008b;5:15. https://doi.org/10.2202/1548-923X.1457.

36. Pitkänen S, Kääriäinen M, Oikarainen A, Tuomikoski A, Elo S, Ruotsalainen H, et al. Healthcare students' evaluation of the clinical learning environment and supervision - a cross-sectional study. Nurse Educ Today. 2018;62:143-9. https://doi.org/10.1016/j.nedt.2018.01.005.

37. Saarikoski M, Isoaho $H$, Warne $T$, Leino-Kilpi $H$. The nurse teacher in clinical practice: developing the new sub-dimension to the clinical learning environment and supervision (CLES) scale. Int J Nurs Stud. 2008;45(8):12337. https://doi.org/10.1016/j.jinurstu.2007.07.009.

38. Saarikoski M, Leino-Kilpi $H$. The clinical learning environment and supervision by staff nurses: developing the instrument. Int J Nurs Stud. 2002; 39(3):259-67. https://doi.org/10.1016/s0020-7489(01)00031-1.

39. Al-Anazi NA, Alosaimi D, Pandaan I, Anthony D, Dyson S. 2019. Evaluating clinical placements in Saudi Arabia with the CLES+T scale. Nurse Educ Pract 2019;39:11-6. https://doi.org/10.1016/j.nepr.2019.07.004.

40. Antohe I, Riklikiene O, Tichelaar E, Saarikoski M. Clinical education and training of student nurses in four moderately new European Union countries: assessment of students' satisfaction with the learning environment. Nurse Educ Pract. 2016;17:139-44. https://doi.org/10.1016/j. nepr.2015.12.005.

41. Fröberg $M$, Leanderson $C$, Fläckmand B, Hedman-Lagerlöf $E$, Björklund $K$, Nilsson $\mathrm{GH}$, et al. Experiences of a student-run clinic in primary care: a mixed-method study with students, patients and supervisors. Scand J Prim Health Care. 2018;36(1):36-46. https://doi.org/10.1080/02813432.2018.142 6143.

42. Ozga D, Gutysz-Wojnicka A, Lewandowski B, Dobrowolska B. The clinical learning environment, supervision and nurse teacher scale (CLES+T): psychometric properties measured in the context of postgraduate nursing education. BMC Nurs. 2020;19:61. https://doi.org/10.1186/s12912-020-004555.

43. Öhman E, Alinaghizadeh $H$, Kaila P, Hult H, Nilsson GH, Salminen $H$. Adaptation and validation of the instrument clinical learning environment and supervision for medical students in primary health care. BMC Med Educ. 2016;16(1):308. https://doi.org/10.1186/s12909-016-0809-8.

44. ALLEA - All European Academies. The European Code of Conduct for Research Integrity. Revised edition. Berlin: ALLEA - All European Academies; 2017. Available from: https://ec.europa.eu/research/participants/data/ref/h2 020/other/hi/h2020-ethics_code-of-conduct_en.pdf. Cited 2019 April 8

45. Finnish Advisory Board on Research Integrity. Responsible conduct of research and procedures for handling allegations of misconduct in Finland. Guidelines of the Finnish Advisory Board on Research Integrity, 2012. Available from: https://www.tenk.fi/sites/tenk.fi/files/HTK_ohje_2012.pdf. Cited 2019 Apr 8.

46. Regulation (EU) 2016/679 on the protection of natural persons with regard to the processing of personal data and on the free movement of such data. The European Parliament and the Council of the European Union; 2016. Available from: http://data.europa.eu/eli/reg/2016/679/oj. Cited 2021 Jan 8.

47. Dijk SW, Duijzer EJ, Wienold M. Role of active patient involvement in undergraduate medical education: a systematic review. BMJ Open. 2020;10: e037217. https://doi.org/10.1136/bmjopen-2020-037217.

48. Kandal HM, Kristiansen J, Uhrenfeldt L. Nursing students experienced personal inadequacy, vulnerability and transformation during their patient care encounter: a qualitative metasynthesis. Nurse Educ Today. 2018;64:99_ 107. https://doi.org/10.1016/j.nedt.2018.02.008.

49. Saarikoski M. Methodological issues and development of the CLES scales. In: Saarikoski M, Strandell-Laine C, editors. The CLES-scale: an evaluation tool for healthcare education. Cham: Springer; 2018. p. 17-29. https://doi.org/1 0.1007/978-3-319-63649-8_3.
50. Bos E, Alinaghizadeh H, Saarikoski M, Kaila P. Validating the 'clinical learning environment, supervision and nurse teacher' CLES+T instrument in primary healthcare settings using confirmatory factor analysis. J Clin Nurs. 2012; 21(11-12):1785-8. https://doi.org/10.1111/j.1365-2702.2011.04030.x.

51. Courser M, Lavrakas PJ. Item-nonresponse and the 10-point response scale in telephone surveys. Survey Pract. 2012;5. https://doi.org/10.2911 5/SP-2012-0021.

\section{Publisher's Note}

Springer Nature remains neutral with regard to jurisdictional claims in published maps and institutional affiliations.
Ready to submit your research? Choose BMC and benefit from:

- fast, convenient online submission

- thorough peer review by experienced researchers in your field

- rapid publication on acceptance

- support for research data, including large and complex data types

- gold Open Access which fosters wider collaboration and increased citations

- maximum visibility for your research: over $100 \mathrm{M}$ website views per year

At BMC, research is always in progress.

Learn more biomedcentral.com/submissions 